\title{
Depression and anxiety among university students in Hong Kong
}

\author{
Kevin WC Lun *, CK Chan, Patricia KY Ip, Samantha YK Ma, WW Tsai, CS Wong, Christie HT Wong, \\ TW Wong, D Yan
}

\section{A B S T R A C T}

Introduction: Entry into tertiary education is a critical juncture where adolescents proceed to adulthood. This study aimed to determine the prevalence of depression and anxiety, and factors associated with such symptoms, among university undergraduate students in Hong Kong.

Methods: A cross-sectional questionnaire study was employed. A total of 1200 undergraduate students from eight University Grants Committee-funded universities were invited to complete three sets of questionnaires, including the 9-item patient health questionnaire for screening of depressive symptoms, the 7-item generalised anxiety disorder scale for screening of anxiety symptoms, and a sociodemographic questionnaire.

Results: Among the valid responses $(n=1119)$ analysed, 767 (68.5\%) respondents indicated mild to severe depressive symptoms, which were associated with mild to severe anxiety symptoms. Several lifestyle and psychosocial variables, including regular exercise, self-confidence, satisfaction with academic performance, and optimism towards the future were inversely related with mild to severe depressive

This article was published on 24 Sep 2018 at www.hkmj.org. symptoms. A total of 599 (54.4\%) respondents indicated mild to severe anxiety symptoms, which were associated with level of academic difficulty.

Satisfaction with friendship, sleep quality, and selfconfidence were inversely associated with mild to severe anxiety symptoms.

Conclusion: Morethan $50 \%$ of respondents expressed some degree of depressive and anxiety symptoms (68.5\% and $54.4 \%$, respectively). Approximately $9 \%$ of respondents exhibited moderately severe to severe depressive symptoms; $5.8 \%$ exhibited severe anxiety symptoms. Respondents reporting regular exercise, higher self-confidence, and better satisfaction with both friendship and academic performance had fewer depressive and anxiety symptoms.

\section{Hong Kong Med J 2018;24:466-72}

DOI: $10.12809 / \mathrm{hkmj} 176915$

KWC Lun *

CK Chan

PKY Ip

SYK Ma

WW Tsai

CS Wong

CHT Wong

TW Wong

D Yan

Li Ka Shing Faculty of Medicine, The University of Hong Kong, Pokfulam, Hong Kong

* Corresponding author: lunkwc@gmail.com

New knowledge added by this study

- Up to $9 \%$ of university students in Hong Kong exhibit moderately severe to severe depressive symptoms.

- Up to $5.8 \%$ of university students in Hong Kong exhibit severe anxiety symptoms.

- Respondents reporting regular exercise, higher self-confidence, and better satisfaction with both friendship and academic performance had fewer depressive and anxiety symptoms.

Implications for clinical practice or policy

- Health care workers and organisations such as universities should be aware of potential depression and anxiety among university undergraduate students.

- Adolescents and young adults in Hong Kong should be educated, to raise social awareness of depression and anxiety among university undergraduate students.

\section{Introduction}

Recently, an increased incidence of suicide among students has triggered immense public concern regarding the mental health of adolescents and young adults. In 2014, there were 52 suicides in the age-group 15 to 24 years. The number of suicides in this age-group increased in subsequent years to 68 in 2015 and 75 in $2016 .{ }^{1}$ A report from the Centre for Health Protection in Hong Kong showed that, in 2012, the prevalences of mild, moderate, and severe depressive symptoms in adolescents and children were $36.4 \%, 14.7 \%$, and $4.2 \%$, respectively. ${ }^{2}$ The Population Health Survey 2003/2004 conducted collaboratively by the Department of Health and the Department of Community Medicine of the University of Hong Kong revealed that the median score for the State-Trait Anxiety Inventory was highest in those aged 25 to 34 years, whereas the 
median score for the Centre for Epidemiologic Studies Depression Scale was highest in those aged 15 to 34 years. ${ }^{3}$ A web-based survey targeting firstyear students receiving tertiary education in Hong Kong concluded that, in 2006, the prevalence of depression was $20.9 \%$, while that of anxiety was 41.2\%. ${ }^{4}$ Another recent study, the Hong Kong Mental Morbidity Survey, ${ }^{5}$ revealed that the most common mental problem in Hong Kong was mixed anxiety and depressive disorder; moreover, there was a strong association between anxiety symptoms and depressive symptoms.

According to the Diagnostic and Statistical Manual of Mental Disorders, published by the American Psychiatric Association, major depressive disorder is defined as the presence of five or more of the listed symptoms for most of the days during the same 2-week period; at least one of the symptoms must be either depressed mood or loss of interest or pleasure. Notably, these symptoms should reflect a change from previous functioning. Generalised anxiety disorder (GAD) is characterised by excessive worries that cause distress and interfere with psychosocial functioning. These worries frequently happen without precipitants, exhibit longer durations, and are accompanied by three or more of the six listed additional symptoms.

Various factors associated with major depressive disorder and GAD have been identified, including alcohol use, illicit drug use, tobacco use, and level of physical activity. ${ }^{6}$ However, evidence for an association between academic pressure and these two psychiatric disorders remains unknown among university undergraduate students in Hong Kong. We aimed to provide an update regarding the prevalence of depressive and anxiety symptoms experienced by undergraduate students in Hong Kong, and to identify factors associated with these symptoms.

\section{Methods}

Full-time undergraduate students of the eight universities in Hong Kong that are funded by the University Grants Committee (UGC) were the target participants in this study. A cross-sectional study design was employed and the target number of students to be enrolled from each university was 150; the total target number of students to be recruited was 1200 .

The inclusion criteria for this study were as follows: full-time undergraduate students in the eight UGC-funded universities who were $\geq 18$ years, were able to understand the consent, provide a valid oral consent, comprehend the questionnaire, and had not previously participated in this research. Students who failed to fulfil all inclusion criteria were excluded from the study.

Convenience sampling was employed. Questionnaires were distributed at popular locations

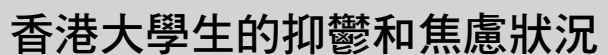

\section{倫偉程、陳重光、葉潔盈、馬慗嘉、蔡偉華、黃智信、 黃晧婷、黃天韻、甄多嘉}

引言：進入高等教育是青少年進入成年期的關鍵時刻。本研究旨在調 查香港大學本科生的抑鬱症和焦慮症的患病率, 以及與此類症狀相關 的因素。

方法：採用橫斷面問卷調查研究。共邀請八所大學教育資助委員會資

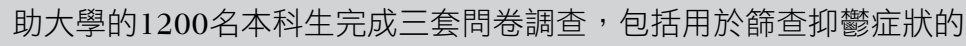
9項患者健康問卷 (PHQ-9) 、用於篩查焦慮症狀的7項廣義焦慮症量 表（GAD-7），以及個人背景資料問卷。

結果：在有效的問卷中（ $\mathrm{n}=1119 ） ， 767$ 名（68.5\%）受訪者有輕度 至重度抑稂症狀, 這與輕度至重度焦慮症狀相關。另一方面, 一些生 活習慣和心理狀況, 包括經常運動、有自信心、滿意學業成績, 以及 對未來樂觀與輕度至重度抑鬱症狀呈負相關。另外, 599名（54.4\%） 受訪者有輕度至重度焦慮症狀, 這與學業困難程度相關。另一方面, 對友誼和睡眠質量滿意, 以及有自信心與輕度至重度焦慮症狀呈負相 關。

結論：超過 50\%受訪者有一定程度的抑鬱和焦慮症狀（分別為68.5\% 和 $54.4 \%$ ）。大約 $9 \%$ 受訪者有中重度至嚴重抑鬱症狀； $5.8 \%$ 有嚴重焦 慮症狀。研究發現經常運動、有自信心、對友誼和學習成績滿意的受 訪者較少出現抑䉮和焦慮症狀。

within all eight university campuses on school days in September and October 2016. Participants were asked to complete three sets of questionnaires, including the 9-item Patient Health Questionnaire (PHQ-9) for screening of depressive symptoms, the 7-item GAD scale (GAD-7) for screening of anxiety symptoms, and a socio-demographic questionnaire to identify factors associated with depressive and anxiety symptoms. ${ }^{7,8}$ When completed questionnaires were being returned, respondents were reminded that they would not be able to withdraw from the study after returning the questionnaires, as the questionnaires did not contain any personal identifying information to allow individual retrieval.

The PHQ-9 was adopted to screen for depressive symptoms in this study. Both Chinese and English versions were provided. The PHQ-9 has been shown to be a valid and reliable tool for assessing depressive symptoms in the Hong Kong general population. ${ }^{7,8}$ Another study showed that the PHQ-9 was a useful tool to detect both major depression and subthreshold depression. ${ }^{9}$ According to the PHQ-9, a score of $<5$ was defined as noneminimal depressive symptoms, score of 5 to 9 as mild, score of 10 to 14 as moderate, score of 15 to 19 as moderately severe, and score of $\geq 20$ as severe.

The GAD-7 is a practical self-report anxiety questionnaire that is generally used in out-patient and primary care settings for referral to a psychiatrist to confirm the diagnosis of GAD. Both Chinese and 


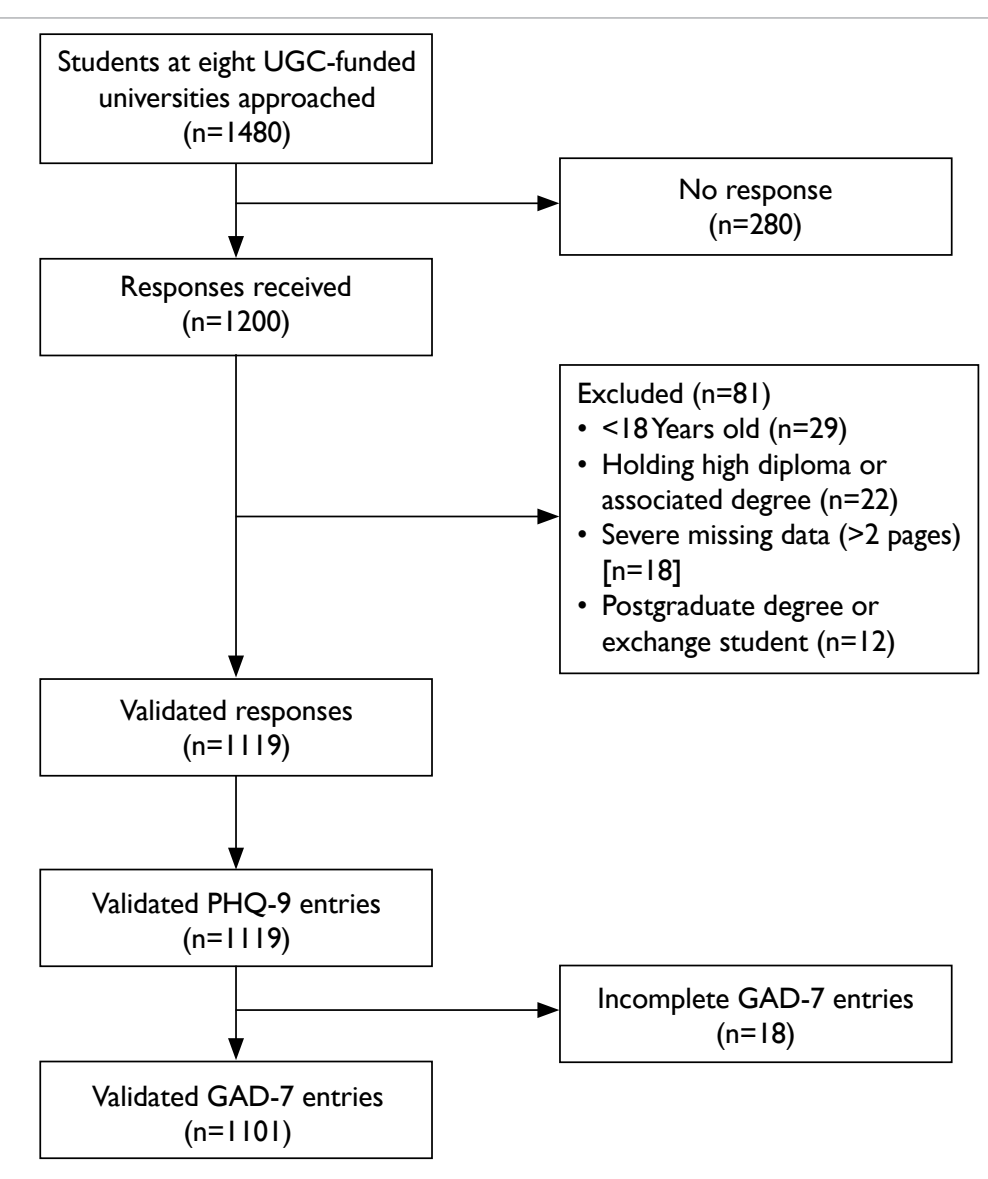

FIG. Flow chart showing the number of validated questionnaires from the eight UGC-funded universities included in the study

Abbreviations: GAD-7 = 7-item Generalised Anxiety Disorder scale; PHQ-9 = 9-item

Patient Health Questionnaire; UGC = University Grants Committee

English versions were available. The adoption of GAD-7 in this study was due to its good reliability, as well as its criteria, construct, and factorial and procedural validity. ${ }^{10,11}$ According to the GAD-7, a score of $<5$ was defined as none-minimal anxiety symptoms, score of 5 to 9 as mild, score of 10 to 14 as moderate, and score of $\geq 15$ as severe.

Descriptive analysis was performed to summarise the demographics and statuses of depressive and anxiety symptoms of the respondents. A binary logistic regression was conducted to ascertain the effects of various covariates on the odds of exhibiting mild to severe depressive symptoms, on the basis of PHQ-9 results. A PHQ-9 score of $<5$ was defined as no depressive symptoms, while a score of $\geq 5$ was defined as mild to severe depressive symptoms. Another binary logistic regression was used to ascertain the effects of multiple covariates on the odds that participants would exhibit mild to severe anxiety symptoms, on the basis of GAD-7 results. A GAD-7 score of $<5$ was defined as no anxiety symptoms, while a score of $\geq 5$ was defined as mild to severe anxiety symptoms. A P value of $<0.05$ was regarded as a significant difference.

\section{Results}

In total, 1480 undergraduate students from the eight UGC-funded universities were approached from 6 September 2016 to 3 October 2016. From these, 1200 completed questionnaires were collected, for a response rate of $81.1 \%$. A total of 81 students did not meet at least one of the inclusion criteria and their responses were subsequently excluded from analysis (Fig). The remaining 1119 students fulfilled all inclusion criteria and their responses were analysed by SPSS (Mac version 24; IBM Corp, Armonk [NY], United States).

The mean (standard deviation) age of the respondents was 19.81 (1.48) years (range, 18-29 years). Among the respondents, 426 (38.1\%) were male and 693 (61.9\%) were female. Most respondents were Chinese (92.7\%). The respondents' demographics are shown in Table 1.

Among the 1119 valid questionnaires analysed, 767 (68.5\%) were found to have mild to severe depressive symptoms (Table 2).

For screening of anxiety symptoms, 18 of the 1119 respondents were excluded because they did not complete the GAD-7 questionnaires; therefore, results are based on the 1101 valid responses. A total of 599 (54.4\%) respondents were found to have mild to severe anxiety symptoms. A higher prevalence of anxiety was observed in females than males in all three categories of severity (Table 3 ).

The binary logistic regression model for the effects of multiple covariates on the odds of having mild to severe depressive symptoms, on the basis of the PHQ-9 results, was statistically significant with $X^{2}=375.006, P<0.001$, with 18 degrees of freedom (Table 4). The model explained $43.1 \%$ of the variance in depression severity, as shown by Nagelkerke $\mathrm{R}^{2}$, and correctly classified $79.6 \%$ of the cases. Mild to severe anxiety symptoms, as screened by GAD-7, were significantly associated with mild to severe depressive symptoms $(\mathrm{P}<0.001)$. In contrast, several lifestyle and psychosocial variables, including regular exercise $(\mathrm{P}<0.001)$, self-confidence $(\mathrm{P}=0.01)$, satisfaction with academic performance $(\mathrm{P}=0.019)$, and optimism towards the future $(\mathrm{P}<0.001)$ were inversely related to mild to severe depressive symptoms.

Another binary logistic regression model for the effects of multiple covariates on the odds of having mild to severe anxiety symptoms, on the basis of the GAD-7 results, was statistically significant with $X^{2}=374.842, \mathrm{P}<0.001$, with 20 degrees of freedom (Table 5). The model explained $41.3 \%$ of the variance in depression severity, as shown by Nagelkerke $\mathrm{R}^{2}$, and correctly classified $76.9 \%$ of the cases. Mild to severe anxiety symptoms were associated with level of academic difficulty $(\mathrm{P}=0.028)$ and mild to severe depressive symptoms, as screened by PHQ-9 $(\mathrm{P}<0.001)$. Certain lifestyle and 
TABLE I. Demographics of respondents

\begin{tabular}{|c|c|c|c|}
\hline & \multicolumn{2}{|c|}{ Gender } & \multirow[t]{2}{*}{ Tota } \\
\hline & Male & Female & \\
\hline Valid questionnaires & 426 & 693 & 1119 \\
\hline \multicolumn{4}{|l|}{ University } \\
\hline The University of Hong Kong & 51 & 88 & 139 \\
\hline $\begin{array}{l}\text { The Chinese University of } \\
\text { Hong Kong }\end{array}$ & 33 & 90 & 123 \\
\hline $\begin{array}{l}\text { Hong Kong University of } \\
\text { Science and Technology }\end{array}$ & 85 & 58 & 143 \\
\hline $\begin{array}{l}\text { Hong Kong Polytechnic } \\
\text { University }\end{array}$ & 57 & 94 & 151 \\
\hline City University of Hong Kong & 53 & 81 & 134 \\
\hline Hong Kong Baptist University & 40 & 107 & 147 \\
\hline $\begin{array}{l}\text { Education University of Hong } \\
\text { Kong }\end{array}$ & 59 & 76 & 135 \\
\hline Lingnan University & 48 & 99 & 147 \\
\hline \multicolumn{4}{|l|}{ Year of study } \\
\hline 1 & 95 & 165 & 260 \\
\hline 2 & 123 & 220 & 343 \\
\hline 3 & 92 & 146 & 238 \\
\hline 4 & 101 & 139 & 240 \\
\hline 5 & 5 & 10 & 15 \\
\hline Missing & 10 & 13 & 23 \\
\hline \multicolumn{4}{|l|}{ Age (years) } \\
\hline 18 & 75 & 156 & 231 \\
\hline 19 & 105 & 189 & 294 \\
\hline 20 & 103 & 160 & 263 \\
\hline 21 & 88 & 122 & 210 \\
\hline 22 & 20 & 45 & 65 \\
\hline 23 & 23 & 14 & 37 \\
\hline $24-29$ & 12 & 7 & 19 \\
\hline \multicolumn{4}{|l|}{ Ethnicity } \\
\hline Chinese & 389 & 648 & 1037 \\
\hline Non-Chinese & 18 & 19 & 37 \\
\hline Missing & 19 & 26 & 45 \\
\hline
\end{tabular}

TABLE 2. Results of the PHQ-9 $(n=1119)^{*}$

\begin{tabular}{|c|c|c|c|c|}
\hline \multirow[t]{2}{*}{ PHQ-9 score } & \multicolumn{2}{|c|}{ Gender } & \multirow[t]{2}{*}{ Total } & \multirow{2}{*}{$\begin{array}{c}95 \% \\
\text { Confidence } \\
\text { interval }\end{array}$} \\
\hline & Male & Female & & \\
\hline $\begin{array}{l}\text { None-minimal } \\
(<5)\end{array}$ & $143(12.8)$ & $209(18.7)$ & 352 (31.5) & - \\
\hline Mild (5-9) & $163(14.6)$ & $302(27.0)$ & $465(41.6)$ & $38.6-44.5$ \\
\hline $\begin{array}{l}\text { Moderate } \\
(10-14)\end{array}$ & $77(6.9)$ & 124 (11.1) & $201(18.0)$ & $15.8-20.3$ \\
\hline $\begin{array}{l}\text { Moderately } \\
\text { severe }(15-19)\end{array}$ & $32(2.9)$ & $45(4.0)$ & $77(6.9)$ & $5.5-8.5$ \\
\hline Severe $(\geq 20)$ & $11(1.0)$ & $13(1.2)$ & $24(2.1)$ & $1.4-3.2$ \\
\hline
\end{tabular}

Abbreviation: PHQ-9 = 9-item Patient Health Questionnaire

* Data are shown as No. (\%) of respondents, unless otherwise specified
TABLE 3. Results of the GAD-7 $(n=|| 0 \mid)^{*}$

\begin{tabular}{lcccc}
\hline GAD-7 score & \multicolumn{2}{c}{ Gender } & Total & $\begin{array}{c}95 \% \\
\text { Confidence } \\
\text { interval }\end{array}$ \\
\cline { 2 - 3 } & Male & Female & & - \\
\hline $\begin{array}{l}\text { None-minimal } \\
(<5)\end{array}$ & $209(19.0)$ & $293(26.6)$ & $502(45.6)$ & - \\
Mild (5-9) & $133(12.1)$ & $246(22.3)$ & $379(34.4)$ & $31.6-37.3$ \\
$\begin{array}{l}\text { Moderate } \\
(10-14)\end{array}$ & $52(4.7)$ & $104(9.4)$ & $156(14.2)$ & $12.2-16.4$ \\
Severe ( $\geq 15)$ & $24(2.2)$ & $40(3.6)$ & $64(5.8)$ & $4.5-7.4$ \\
\hline $\begin{array}{l}\text { Abbreviation: GAD-7 = 7-item Generalised Anxiety Disorder } \\
\text { scale }\end{array}$ \\
$\begin{array}{l}\text { Data are shown as No. (\%) of respondents, unless otherwise } \\
\text { specified }\end{array}$
\end{tabular}

psychosocial variables, including satisfaction with friendship ( $\mathrm{P}=0.001)$, sleep quality $(\mathrm{P}=0.003)$, and self-confidence $(\mathrm{P}=0.003)$ were inversely associated with mild to severe anxiety symptoms.

\section{Discussion}

The results revealed that $68.5 \%$ of respondents had mild to severe depressive symptoms and $54.4 \%$ had mild to severe anxiety symptoms. These rates are higher than and comparable to the results of a similar survey conducted by the University of Hong Kong 10 years ago, respectively. ${ }^{4}$ This could be attributed to the increasing academic pressure after major reforms of the education system in Hong Kong, ${ }^{12}$ uncertainties in career prospects due to fluctuations in the socio-political environment, and the more prevalent use of social media. ${ }^{13}$

This study revealed that mild to severe depressive symptoms, as screened by PHQ-9, were associated with mild to severe anxiety symptoms, as screened by GAD-7. This is consistent with previous studies, including a study in patients with depression showing that $85 \%$ of those with major depression were also diagnosed with generalised anxiety. ${ }^{14}$ Sharing common risk factors and symptoms may explain their co-existence. ${ }^{15,16}$ Another study has shown that anxiety is more frequently an antecedent of depression, but the reverse relationship was not observed. ${ }^{17}$ This could be explained by the withdrawal and submissive techniques adopted by individuals with anxiety, in response to social exclusion..$^{18}$ However, a definite causal relationship remains unclear.

Regular exercise could decrease the occurrence of depression via both physiological and psychological mechanisms. Exercise exerts an excitatory effect on the monoamine and endorphin neurotransmitter systems; notably, monoamines are depleted in patients with depression. ${ }^{19}$ Psychologically, exercise is reported to improve self-esteem and selfperception through self-actualisation and gaining pleasure from an expanded social circle..$^{20}$ 
TABLE 4. Binary logistic regression model for the effects of multiple covariates on the odds of having mild to severe depressive symptoms, based on the 9-item Patient Health Questionnaire

\begin{tabular}{|c|c|c|c|c|}
\hline & Coefficient & Standard error & P value & $\begin{array}{l}\text { Odds ratio ( } 95 \% \\
\text { confidence interval) }\end{array}$ \\
\hline Female gender & -0.301 & 0.185 & 0.103 & $0.74(0.52-1.06)$ \\
\hline Age & -0.064 & 0.086 & 0.456 & $0.94(0.79-1.11)$ \\
\hline Year of study & -0.135 & 0.114 & 0.237 & $0.87(0.70-1.11)$ \\
\hline Satisfaction with family relationship & 0.000 & 0.180 & 0.999 & $1.00(0.70-1.42)$ \\
\hline Satisfaction with current financial situation & -0.208 & 0.141 & 0.142 & $0.81(0.62-1.07)$ \\
\hline Satisfaction with friendship & 0.025 & 0.190 & 0.897 & $1.03(0.71-1.49)$ \\
\hline Ever-smoking & 0.584 & 0.360 & 0.105 & $1.79(0.89-3.64)$ \\
\hline Regular drinking & 0.030 & 0.262 & 0.909 & $1.03(0.62-1.72)$ \\
\hline Regular exercise & -0.642 & 0.179 & $<0.001$ & $0.53(0.37-0.75)$ \\
\hline Ever-use of illicit drugs & 0.767 & 0.763 & 0.315 & $2.15(0.48-9.61)$ \\
\hline Any physical discomfort/chronic illnesses & -0.136 & 0.311 & 0.663 & $0.87(0.47-1.61)$ \\
\hline Self-confidence & -0.392 & 0.152 & 0.010 & $0.68(0.50-0.91)$ \\
\hline Satisfaction with academic performance & -0.388 & 0.166 & 0.019 & $0.68(0.49-0.94)$ \\
\hline Self-reported study workload & 0.085 & 0.181 & 0.640 & $1.09(0.76-1.55)$ \\
\hline Level of academic difficulty & 0.262 & 0.207 & 0.207 & $1.30(0.87-1.95)$ \\
\hline Satisfaction with career prospects & 0.219 & 0.142 & 0.122 & $1.25(0.94-1.64)$ \\
\hline Optimism towards the future & -0.593 & 0.148 & $<0.001$ & $0.55(0.41-0.74)$ \\
\hline Mild to severe anxiety & 2.354 & 0.187 & $<0.001$ & $10.53(7.30-15.18)$ \\
\hline Constant & 4.112 & 1.716 & 0.017 & 61.05 \\
\hline
\end{tabular}

TABLE 5. Binary logistic regression model for the effects of multiple covariates on the odds of having mild to severe anxiety symptoms, based on the 7-item Generalised Anxiety Disorder scale

\begin{tabular}{|c|c|c|c|c|}
\hline & Coefficient & Standard error & $P$ value & $\begin{array}{l}\text { Odds ratio ( } 95 \% \\
\text { confidence interval) }\end{array}$ \\
\hline Female gender & 0.319 & 0.169 & 0.059 & $1.38(0.99-1.92)$ \\
\hline Age & -0.010 & 0.079 & 0.903 & $0.99(0.85-1.16)$ \\
\hline Year of study & 0.010 & 0.104 & 0.923 & $1.01(0.82-1.24)$ \\
\hline Satisfaction with family relationship & 0.106 & 0.163 & 0.516 & $1.11(0.81-1.53)$ \\
\hline Satisfaction with current financial situation & 0.120 & 0.127 & 0.346 & $1.13(0.88-1.45)$ \\
\hline Satisfaction with friendship & -0.598 & 0.173 & 0.001 & $0.55(0.39-0.77)$ \\
\hline Ever-smoking & -0.272 & 0.312 & 0.382 & $0.76(0.41-1.40)$ \\
\hline Regular drinking & 0.250 & 0.234 & 0.285 & $1.29(0.81-2.03)$ \\
\hline Regular exercise & 0.116 & 0.166 & 0.485 & $1.12(0.81-1.56)$ \\
\hline Ever-use of illicit drugs & 0.126 & 0.667 & 0.851 & $1.13(0.31-4.19)$ \\
\hline Any physical discomfort/chronic illnesses & 0.165 & 0.278 & 0.552 & $1.18(0.68-2.04)$ \\
\hline Average hours of sleep & -0.003 & 0.063 & 0.968 & $1.00(0.88-1.13)$ \\
\hline Sleep quality & -0.418 & 0.139 & 0.003 & $0.66(0.50-0.87)$ \\
\hline Self-confidence & -0.400 & 0.136 & 0.003 & $0.67(0.51-0.88)$ \\
\hline Satisfaction with academic performance & -0.007 & 0.146 & 0.964 & $0.99(0.75-1.32)$ \\
\hline Self-reported study workload & 0.026 & 0.169 & 0.878 & $1.03(0.74-1.43)$ \\
\hline Level of academic difficulty & 0.400 & 0.183 & 0.028 & $1.49(1.04-2.13)$ \\
\hline Satisfaction with career prospects & -0.223 & 0.131 & 0.089 & $0.80(0.62-1.04)$ \\
\hline Optimism towards the future & -0.253 & 0.131 & 0.053 & $0.78(0.60-1.00)$ \\
\hline Mild to severe depression & 2.288 & 0.190 & $<0.001$ & $9.86(6.79-14.31)$ \\
\hline Constant & 0.684 & 1.611 & 0.671 & 1.98 \\
\hline
\end{tabular}


Psychosocial factors, including higher selfconfidence, satisfaction with academic performance, and optimism towards the future are inversely related to depressive symptoms. These could be the presentation or consequences of depression; these factors may have protective effects against developing depression. ${ }^{21}$ Optimism towards the future, apart from personal factors, is also related to community factors. Risk factors include community disadvantage, safety, and discrimination; an important protective factor is community connectedness. These factors were associated with depressive symptoms. ${ }^{22}$ This implies that, in addition to promoting personal mental health, community-level risk and protective factors that affect individuals' optimism towards future are sufficiently important to receive broader attention.

For the analysis of anxiety, the level of academic difficulty was associated with mild to severe anxiety symptoms. A higher level of academic difficulty may create greater stress and anxiety for students; subsequent unsatisfactory academic results may completethe vicious cycle. Severaltips were suggested by the Anxiety and Depression Association of America (ADAA) regarding test anxiety reduction. ${ }^{23}$ Female gender was not associated with mild to severe anxiety symptoms, which conflicts with previous studies.$^{15}$ No clear causality was identified, but some potential aetiologies include higher stress levels from academic and interpersonal issues.

Satisfaction with friendship, sleep quality, and self-confidence were three factors inversely associated with mild to severe anxiety symptoms. Having good interpersonal relationships with peers could be a protective factor against anxiety; however, symptoms of anxiety may also hinder friendship, thus explaining the inverse relationship. Insomnia is a symptom of anxiety. According to a survey conducted by ADAA, worrying about falling asleep at night was identified as a cause for an increased level of anxiety ${ }^{24}$ Recommendations that could help in falling asleep and achieving better sleep quality include maintaining 7 to 9 hours of uninterrupted sleep, establishing a regular bedtime routine, and avoiding electronic gadgets, coffee, and tea, as well as designing a relaxing environment for sleeping. ${ }^{24}$ Lack of self-confidence could be a cause of anxiety, but anxiety symptoms could also diminish one's selfconfidence. A bilateral association is possible.

There were several limitations in our study. Firstly, as with all cross-sectional studies, it was not possible to establish causality between the identified factors and symptoms of depression and anxiety. Hence, the identified factors are regarded as associated factors, which could be either the causes or the results of depression or anxiety. To further explore the relationships between these factors and symptoms of depression and anxiety, we reviewed the available literature to provide supporting evidence.
Secondly, convenience sampling was adopted, but there could be self-selection bias when inviting students to complete the questionnaires, limited by the locations and times at which questionnaire distribution was conducted. The questionnaires were distributed in the open areas of the eight UGCfunded universities in Hong Kong. Withdrawn university students affected by depression or anxiety might not have been reached or might have refused to participate in the study; hence, the results may be underestimates. Thirdly, we could not attain our target number of 150 students from each university, except from the Hong Kong Polytechnic University. Importantly, this study used screening questionnaires to assess the depressive and anxiety symptoms experienced by the students, but no clinical diagnoses were made by health care professionals. However, with limited resources, the use of validated screening questionnaires was considered a cost-effective approach to explore the situation in general and thus was used in this study. Possible directions for further studies include the implementation of stratified random sampling, expansion of the sample size of the study, and performance of a reliability test to reduce information bias. Including detailed backgrounds of students' disciplines and faculties, as well as ensuring a diverse population to include both local and nonlocal students, as well as Chinese-speaking and non-Chinese-speaking students, could allow further subgroup analysis; students from different faculties may experience depressive symptoms or anxiety symptoms at different severities due to differences in curricula. In this research, participants who were screened to have depressive and/or anxiety symptoms were not notified because of the lack of identifiable personal information. Provision of the results to participants and recommendations regarding helpseeking information are suggested for future studies. This study result may not fully reflect the severity of depressive and anxiety symptoms among students, as the study method could not reach severely depressed individuals who had socially isolated themselves.

\section{Conclusion}

This study showed that over $50 \%$ of university students in the eight UGC-funded universities expressed some degree of depressive symptoms $(68.5 \%)$ or anxiety symptoms (54.4\%). Notably, $9 \%$ of these university students exhibited moderate to severe depressive symptoms and $5.8 \%$ of the studied students showed severe anxiety symptoms. Students with regular exercise, higher self-confidence, better satisfaction with academic performance, and more optimism towards the future experienced fewer depressive symptoms. Students with better satisfaction with friendship, better sleep quality, higher self-confidence, and lower levels of academic difficulty experienced fewer anxiety symptoms. 


\section{Author contributions}

Concept or design of study: KWC Lun, CK Chan.

Acquisition of data: All authors.

Analysis or interpretation of data: All authors.

Drafting of the article: All authors.

Critical revision for important intellectual content: KWC Lun, CK Chan.

\section{Acknowledgement}

We thank Dr LM Ho, assistant IT director of the Division of Epidemiology and Biostatistics of School of Public Health of the University of Hong Kong, for his statistical support and advice in conducting this study. We also thank the School of Public Health of the University of Hong Kong, for its support in conducting this study.

\section{Declaration}

All authors have disclosed no conflicts of interest. All authors had full access to the data, contributed to the study, approved the final version for publication, and take responsibility for its accuracy and integrity.

\section{Funding/support}

The LKS Faculty of Medicine, University of Hong Kong reimbursed project expenses under the title of Health Research Project for HKD500.

\section{Ethical approval}

This study was reviewed and approved by the Institutional Review Board of the University of Hong Kong/Hospital Authority Hong Kong West Cluster.

\section{References}

1. Hong Kong Jockey Club Centre for Suicide Research and Prevention, The University of Hong Kong. Statistics. Available from: https://csrp.hku.hk/statistics/. Accessed 18 Sep 2018.

2. Centre for Health Protection, Department of Health, Hong Kong SAR Government. Depression: beyond feeling blue. Non-Communicable Diseases Watch 2012. Available from: https://www.chp.gov.hk/files/pdf/ncd_watch_sep2012.pdf. Accessed 20 Apr 2016.

3. Centre for Health Protection, Department of Health, Hong Kong SAR Government. Population Health Survey 2003/2004. Collaborative project of Department of Health and Department of Community Medicine, University of Hong Kong, Available from: https://www.chp.gov.hk/files/ pdf/report_on_population_health_survey_2003_2004 en.pdf. Accessed 20 Apr 2016.

4. Wong JG, Cheung EP, Chan KK, Ma KK, Tang SW. Webbased survey of depression, anxiety and stress in first-year tertiary education students in Hong Kong. Aust N Z J Psychiatry 2006;40:777-82.

5. Lam LC, Wong CS, Wang MJ, et al. Prevalence, psychosocia correlates and service utilization of depressive and anxiety disorders in Hong Kong: the Hong Kong Mental Morbidity Survey (HKMMS). Soc Psychiatry Psychiatr Epidemiol 2015;50:1379-88.

6. Cairns KE, Yap MB, Pilkington PD, Jorm AF. Risk and protective factors for depression that adolescents can modify: a systematic review and meta-analysis of longitudinal studies. J Affect Disord 2014;169:61-75.
7. Yu X, Tam WW, Wong PT, Lam TH, Stewart SM. The Patient Health Questionnaire-9 for measuring depressive symptoms among the general population in Hong Kong. Compr Psychiatry 2012;53:95-102.

8. Wang W, Bian Q, Zhao Y, et al. Reliability and validity of the Chinese version of the Patient Health Questionnaire (PHQ-9) in the general population. Gen Hosp Psychiatry 2014;36:539-44.

9. Martin A, Rief W, Klaiberg A, Braehler E. Validity of the Brief Patient Health Questionnaire Mood Scale (PHQ-9) in the general population. Gen Hosp Psychiatry 2006;28:71-7.

10. Spitzer RL, Kroenke K, Williams JB, Löwe B. A brief measure for assessing generalized anxiety disorder: the GAD-7. Arch Intern Med 2006;166:1092-7.

11. Tong X, An D, McGonigal A, Park SP, Zhou D. Validation of the Generalized Anxiety Disorder-7 (GAD-7) among Chinese people with epilepsy. Epilepsy Res 2016;120:31-6.

12. Yeh YC, Yen CF, Lai CS, Huang CH, Liu KM, Huang IT. Correlations between academic achievement and anxiety and depression in medical students experiencing integrated curriculum reform. Kaohsiung J Med Sci 2007;23:379-86.

13. O'Keeffe GS, Clarke-Pearson K, Council on Communications and Media. The impact of social media on children, adolescents, and families. Pediatrics 2011;127:800-4.

14. Hall RC, Platt DE, Hall RC. Suicide risk assessment: a review of risk factors for suicide in 100 patients who made severe suicide attempts. Evaluation of suicide risk in a time of managed care. Psychosomatics 1999;40:18-27.

15. Blanco C, Rubio J, Wall M, Wang S, Jiu CJ, Kendler KS. Risk factors for anxiety disorders: common and specific effects in a national sample. Depress Anxiety 2014;31:756-64.

16. van Ameringen M. Comorbid anxiety and depression in adults: Epidemiology, clinical manifestations, and diagnosis. 15 Jun 2017. Available from: https://www.uptodate.com/ contents/comorbid-anxiety-and-depression-in-adultsepidemiology-clinical-manifestations-and-diagnosis. Accessed 24 Jul 2017.

17. Muris P. Normal and Abnormal Fear and Anxiety in Children and Adolescents. London: Elsevier; 2007.

18. Richards CS, O'Hara MW, editors. The Oxford Handbook of Depression and Comorbidity. New York: Oxford University Press; 2014.

19. Buckworth J, Dishman RK. Exercise Psychology. Champaign: Human Kinetics; 2002.

20. Faulkner GE, Taylor AH, editors. Exercise, Health and Mental Health: Emerging Relationships. New York: Routledge; 2005.

21. Wang KT. Perfectionism, depression, and self-esteem: a comparison of Asian and Caucasian Americans from a collectivistic perspective [dissertation]. Pennsylvania: The Pennsylvania State University; 2007.

22. Stirling K, Toumbourou JW, Rowland B. Community factors influencing child and adolescent depression: A systematic review and meta-analysis. Aust N Z J Psychiatry 2015;49:869-86.

23. Anxiety and Depression Association of America. Test Anxiety. Available from: https://www.adaa.org/living-withanxiety/children/test-anxiety. Accessed 23 Mar 2017.

24. Anxiety and Depression Association of America. Stress and Anxiety Interferes with sleep. Available from: https://www. adaa.org/understanding-anxiety/related-illnesses/otherrelated-conditions/stress/stress-and-anxiety-interfere. Accessed 23 Mar 2017. 